\title{
Using Supplementary Readings (Short Stories) in Increasing the Conceptual Fluency, the Case of Idioms in English
}

\author{
Elahe Mokhtari (Corresponding author) \\ English Department, Shahreza Branch, Islamic Azad University, Isfahan, Iran \\ Islamic Azad University, Pasdaran Street, Shahraza, Isfahan, Iran \\ E-mail:elahe_m560@yahoo.com \\ Mohammed Reza Talebinezhad \\ English Department, Shahreza Branch, Islamic Azad University, Isfahan, Iran \\ Islamic Azad University, Pasdaran Street, Shahraza, Isfahan, Iran \\ E-mail:rtalebinezhad@yahoo.com
}

Doi:10.7575/aiac.alls.v.5n.1p.134

Received: 08/01/2014

URL: http://dx.doi.org/10.7575/aiac.alls.v.5n.1p.134

Accepted: 27/02/2014

\begin{abstract}
The aim of this research was to probed whether using supplementary readings (short stories containing idioms) increase conceptual fluency of L2 learners. In line with the goal of the study, first, the researcher selected a sample of 30 female lower-intermediate L2 learners from Sadr Private Language Centre in Isfahan. She selected them based on their scores (75 or higher) in the previous term final exam. The researcher divided them into two groups. Then, she held a pre-test containing 30 multiple choice questions and registered their scores out of 30. Questions were mainly taken from the exercises of the book 'Can You Believe It? (1)'. Next, she taught idioms to both groups 15 minutes each session and for thirty sessions, but provided only the experimental group with supplementary readings taken from the mentioned book. After that, she held a post-test containing 30 multiple choice questions and again registered their scores. Questions were taken again from book exercises with a higher level of difficulty comparing to the pre-test. Finally, the researcher compared the results obtained from groups' mean scores, frequency of obtained scores, and t-test on pre-test and posttest. The results of the study showed that the experimental group accomplished far better than the control group on the post-test. It also showed that the experimental group development in terms of conceptual fluency was meaningful and reliable. Therefore, it can be concluded that using supplementary readings has positive effect on developing conceptual fluency of L2 learners.
\end{abstract}

Keywords: idiom, conceptual fluency, metaphorical competence

\section{Introduction}

The whole meaning of a complex lexical construction depends on the meaning of constituent parts, regards the compositionally principle. That is meaning of a expression combining the meaning of the element(i.e .words)that it contains (Cruse, 2006). In expression to which this principle doesn't apply, non-compositionally or brought up. Traditionally idioms are considered to be a representative example of this category. Therefore, mainstream definitions hold that idioms "are restricted collocations which cannot normally be understood from the literal meaning of the words which make them up" (Carter, 1998).

Although there is shortage of agreement, it is generally believed that idioms are used in a broad range of every day situation .since idioms are prevalent, they are linked to L2 proficiency or to move fluency. Many researchers (Ellis, 1997; Yorio, 1989) declare that sufficient knowledge and proper use of idioms in an L2 has a crucial role in communicative competence.

When students lack the communicative competence they cannot present themselves in authentic situations out of class. In a more optimistic view, students enhance verbal fluency which Danesi defines use the ability to produce grammatically and communicatively appropriate discourse in L2 . However, they do not necessarily develop conceptual fluency (including metaphorical competence) which defines as learners capability to apply and understand the concepts of a L2 (Danesi, 2003).

When metaphorical competence is inadequate in typical classroom, L2 learners' writings show a high degree of literalness. After three or four years of study, L2 learners learn nearly no new way of thinking conceptually, but only chiefly on their L1 conceptual base (Danesi, 1992). 
Students should be trained strategies to deal with figurative language, and those strategies would help them take advantage of the semantic transparency of some idioms. Conceptual fluency (including metaphorical competence) can be developed in the classroom if students are taught about the underlying cognitive mechanisms (Irjo, 1993).

Formal instruction created to progress pragmatic skills seemed to be greatly efficient when it focuses on formulaic implicatures (Bouton, 1994). Teaching about orientational metaphors underlying phrasal verbs will result in a better acquisition of idiom (Kövecses \& Szabó, 1996).

Lack of language textbooks and systematic approach to teaching idioms to second and foreign language learners, it is suggested that Source Language (SL) teachers introduce idioms more regularly and systematically to their students. Increased attention to SL idiomaticity is a necessary first step toward creating a community of learners where the teachers and the learners simultaneously develop their own understanding of what they are doing (Allwright, 2006).

To start with the teaching materials, there are three main approaches relating the teaching of figurative language, which contains, between others, idioms and metaphors. The first type of materials gives figurative language (idioms included) as something special, the second exploits the cognitive linguistic view and the third combines figurative language among the various units (Littlemore \& Low, 2006).

It should be noted that idioms are normal rather than special aspect of every day communication. so, a kind of conceptoriented book that includes all the essential information regarding morphosyntactic aspects and appropriateness cues plus authentic language (i.e. figurative language used by native speakers) is a convenient solution to deal with teaching idioms (Danesi, 1995).

\subsection{Statement of the Problem}

It is broadly accepted that teaching and learning idioms is considered to be not the easiest part of vocabulary instruction but rather a stumbling block (Laufer, 1997). Idiomaticity affects in a negative manner the comprehension at the high level (Marton, 1977). In the same vein, idiomatic expressions are hard to percieve and learn even when the two languages are similar in the use and meaning (Kellerman, 1978/ 1986).

L2 learners cannot easily improve conceptual fluency which in turn multiplies the problem of learning idioms. Learners enhance verbal fluency which is the ability to generate grammatically and communicatively suitable discourse in L2 (Danesi, 2003). However, they do not necessarily develop conceptual fluency which is the ability to use and understand the concepts of a L2 (Danesi, 2003).

It has been frequently observed that students produce discourses with a high level of verbal fluency that appears to lack the conceptual appropriateness that describes the identical corresponding discourses of a native speaker (Danesi, 1995).

It seems that L2 learners' difficulty in learning idioms and their lack of conceptual fluency roots in not having enough exposure to L2 idioms in real life situations.

\subsection{Purpose of the Study}

Regarding the above mentioned problems, especially the lack of L2 learners' exposure to idioms in real life situations, the purpose of the current study is to investigate whether using supplementary readings (short stories containing idioms) enhance L2 learners' conceptual fluency.

\subsubsection{Research Question}

To pursue the purpose of the study, the following research question was posed:

Does using supplementary readings (short stories containing idioms) enhance L2 learners' conceptual fluency?

\subsubsection{Research Hypothesis}

To answer the research question, the following hypothesis was formulated:

Using supplementary readings (short stories containing idioms) does not enhance L2 learners' conceptual fluency.

\subsection{Significance of the Study}

Proficiency of appropriate use of idiomatic expressions is a part of important language learning. (Danesi, 1992). On the one hand, because of the extensive use of idiomatic expressions in daily dialogues, and in L2 learners need to learn how to use idiomatic expressions properly to develop speech fluency (De Caro, 2009; Oppenheim, 2000). On the other hand, these expressions often pose particular problems to L2 learning (Cooper, 1998; Fong, 2006; Steinel, Hulstijn, and Steinel, 2007). so, understanding how idiomatic expressions are shown in the mental lexicon of the L2 learners is very important. In the same line, the present study tries to investigate the effect of using supplementary readings (short stories containing idioms) on the possible improvement of conceptual fluency in L2 learners.

\section{Literature Review}

Idioms are a colorful and appealing aspect of English. They are usually used in every types of language, informal and formal, spoken and written. Idioms frequently have a stronger meaning than non-idiomatic phrases. Idioms may also suggest a particular attitude of the person using them, for example humor, disapproval, exasperation or admiration so 
you must use them carefully (Irujo, 1993). Unlike novel phrases, idioms are remembered as essential units. Most native speakers frequently use these units in their conversation; therefore, idioms form a very main part of any natural language (Vanlancker-Sidtis, 2003; Wray, 2003).

Glucksberg (2001) classifies idioms as compositional and non-compositional. Compositional idioms have a semantic relation to the idiomatic meaning. Breaking the ice is an example in which "the word break corresponds to the idiomatic sense of abruptly changing an uncomfortable social situation, and the word ice corresponds to the idiomatic sense of social or interpersonal tension" (Glucksberg, 2001, p.73). Non-compositional idioms have no relation to the meaning of the idiom. By and large has no literal meaning and it is not possible to alter or paraphrase (Glucksberg, 2001, p.73).

Glucksberg (2001) argues that "fixed expressions are recognized the same way as single words, via a process of elimination" (p.70). This means that the beginning of a word or a compound permits the listener or reader to predict its ending .However, regarding expressions like idioms, there may be many beginning with the same word. Thus, predicting the end of an idiom is harder. The prediction depends on when the "keyword" appears. An idiomatic expression where the keyword appears early may be recognized faster than an idiom where the keyword appears late (Glucksberg, 2001).

According to Cooper (1998), people try to analyze idioms in regards of compositionality and to assign independent meanings to the constituents of an idiom, which will shape the overall figurative interpretation. When it is possible to assign meanings to the individual words composing an idiom, like in don't give up the ship, it is also easier to combine these meanings to form a figurative interpretation, as opposed to when meanings cannot be assigned to the individual constituents like in kick the bucket (p.236).

Children acquiring their native language learn compositional and transparent idioms fairly easy and they treat idioms just as ordinary language. Nonetheless, this way of treating the constituents of an idiom just like any other word is sometimes a problem for second language learners since they try to translate the literal meaning into their native language (Glucksberg, 2001). In addition, the understanding of an idiom is also depending on if the idiom is used conventionally, i.e. as an idiom, or unconventionally, that is, literally (Gibbs, 1980).

A higher degree of transparency as well as context facilitates the general understanding of an idiom (Danesi, 1995).

Talking about idiomatic expressions, attention should be paid to all parts of its circumstances, such as metaphorical competence, conceptual metaphors, followed by conceptual fluency.

To be conceptually fluent in a language is to know, in big part, how that language "reflects" or encodes concepts on the basis of metaphorical reasoning. This kind of knowledge, like gr communicative (pragmatic)and grammatical knowledge, is by and large unconscious in native speakers (Danesi, 1995).

Metaphors provide a means for understanding something abstract in terms of something concrete. These metaphors inform normal ways of talking about life situation. They are not just "poetic" but rather determine "usage" in our language. Our ordinary conceptual system, in terms of which we both think and act, is basically metaphorical in nature (Lakoff \& Johnson, 1980). Research offers that at least a fixed part of the human mind is 'programmed' to think metaphorically (see Lakoff and Johnson, 1980; Lakoff, 1987; Johnson, 1987; Danesi, 1992). Metaphor likely underlies the showing of an important part of our common concepts.

A subject matter in the study of Second Language Acquisition (SLA) in lately years is the extent to which learners of an L2 learn how to state themselves in the target language using figurative speech going with the culture. It is called the disregarded dimension in L2 teaching (Danesi, 1992). Gibbs (1994), in researching the psycholinguistic facts on figurative language, explains that "in proper contexts people mostly use the metaphorical asset of a message rather than its literal meaning" (p. 63). so, metaphors are part of communicative interaction (Lantolf \& Thorne, 2006).

The conceptual system is an image of reality on which is based every part of human symbolic behavior. Our religious beliefs, figurative arts, social organization and language are rooted in it in some necessary way (Lakoff \& Johnson, 1980). But this conceptual system is not something we are usually aware of.

Because communication is based on the similiar conceptual system that we use in acting and thinking, language is a significant cause of indication for what that system is like. but, the analysis of language is especially illuminating since language is our primary means of communication. Since the relationship between the notions in the conceptual system is metaphorical, metaphor at the conceptual level turns "understanding and experiencing one kind of thing in terms of another" (Lakoff \& Johnson, 1980). The study of metaphor and its dealings to language and cognition took on a new way in the 1980's with the publication of Lakoff and Johnson's (1980) book Metaphors We Live By and with the advance progress of their ideas later in the decade (Lakoff, 1987; Johnson, 1987). Their fundamental point of contention was that metaphors are not only an ornamentation of language, a poetic refrence or a rhetorical device, but rather metaphors and the capacity to metaphorize are a basic aspect of human cognition. According to their theory (1987), human cognition and behavior is ruled by and mediated through a non-linguistic conceptual system which is basic in how we arrange and comprehend our percepts, thoughts, and consequently reality (p. 43). 
There are many aspects of language learning that are not conceptual, mainly because language learners can get quite fluency in the target language without conceptual fluency. For example, they are possibly perceptual, indexical, denotative or iconic, which can be gained by the foreigny language learners without much difficulty (Kecsks, 1999). however speakers with low level of conceptual fluency will never seem native-like.

Conceptual Fluency Theory holds that underlying any given linguistic system is a conceptual system which serves as the fundemental not merely for language, however for cognitive functioning in general: we speak, perceive, think, and interpret the world in terms of our conceptual system (Danesi, 1992). In acquiring another language, so, L2 learners must express themselves in the TL while utilizing the L2 conceptual system in order to express themselves in a truly native-like fashion. To be conceptually fluent is to be able to partake in a target culture perception of the physical and social world and to interact with it like a native. Figurative language competence has aroused the interest of a number of L2 researchers (Danesi, 1992).

Danesi (1995) debates that "L2 learners do not achieve the fluency level of a native speaker until they have knowledge of "how that language 'reflects' or 'encodes' concepts on the basis of metaphorical reasoning" (p. 5).

Between foreign language learners there is an presumption that no real fluency is possible in a foreign language unless the learner spends some time in the target language country. Every language learner travelling in the target language country uses wrong or nonnative-like construction, phrases and words and has experienced a certain kind of hopeless which is the result of not saying meaning the same way as native speakers. What these learners lack most is conceptual fluency which means knowing how the target language reflects or encodes its concepts on the basis of metaphorical structuring (Danesi, 1992) and other cognitive mechanisms (Kovecses \& Szabo, 1996).

Foreign language learners usually rely on the conceptual base of their mother tongue and they map target language forms on L1 conceptualizations (Kecskes, 1995).so, their problem is basically not grammatical but conceptual. This is why there is nothing like full profiency of a second or foreign language, and this is where multi-competence should be difrentiated from mono-competence. Foreign language learners have not merely to master the grammatical structures and communicative peculiarities of the new language but also, in order to sound native-like, they have to learn to think as native speakers do, understand the world the way native speakers do, and use the language metaphorically as native speakers do (Kecskes, 1995).

\section{Methodology}

As mentioned earlier, previous studies have rarely used idioms as a way to develop conceptual fluency in L2 learners. hence, the goal of the current study was to teach idioms through supplementary readings to increase L2 learners' conceptual fluency.

An experimental method of research was used to collect data and find the possible effects of using supplementary readings (short stories containing idioms) on enhancing L2 learners' conceptual fluency. In interpreting the results, this study mainly used a quantitative approach.

\subsection{Participants}

Participants of the present study were 30 female lower-intermediate L2 learners from Sadr Private Language Centre (SPLC) in Isfahan. They were selected based on their scores ( 75 or higher) in the previous term final exam. Then, they were divided into two groups of 15 students.

\subsection{Material}

The material in the present study was the book 'can you believe it (1)' written by Huizenga in 1996. It was published by OUP publications and included 113 pages, fifteen lessons, review, and appendices in the form of answer key, idiom groups, phrasal verbs, and lexicon.

The logic behind selecting the book was its availability, its frequent publication, its volume, the number of lessons, and being among the best-sellers.

\subsection{Instruments}

Instruments used in the present study were mainly a pre-test and a post-test.

The Pre-test was held to evaluate the students' proficiency level in idioms. It consisted of thirty multiple choice questions. Each choice was an idiom. Idioms were mainly those L2 Learners had learned in previous terms or among more fashionable ones included in the book exercises (see Appendix 1).

The Post-test was also held after teaching idioms and providing one group with short stories containing idioms (supplementary reading) at the end of the term. It also consisted of thirty multiple choice questions taken from the book exercises. Here again, each choice was an idiom. But, this time the idioms were those learners had learned for the first time. Therefore, post-test enjoyed a higher level of difficulty (see Appendix 2).

\subsection{Procedures}

To answer the research question, the researcher conducted the following steps: 
First, the researcher selected a sample of 30 female lower- intermediate level students of SPLC based on their score (75 or higher) in previous term final exam.

Then, she held a pre-test for both groups. It consisted of thirty multiple choice questions containing idioms taken from the exercises of the book 'Can you believe it?' The researcher selected more fashionable idioms and allocated two questions to each lesson. She registered students' score out of thirty for both groups. She also conducted a t-test.

Next, the researcher taught both groups idioms fifteen minutes each session for thirty sessions. She wrote the idioms on the board and gave some intances. At the end of each session she provided only one of the groups with the copies of supplementary readings/ stories to study at home. The stories contained the same idioms taught in the class. Neither the first nor the second group had access to the original book or its exercises.

After that, the researcher held the post-test. It also consisted of thirty multiple choice questions containing idioms taken from the exercises of the book 'Can you believe it?' She allocated two questions to each lesson. This time the researcher selected idioms which students had learned in class and rarely heard before. Again she registered students' score out of thirty for both groups. She also conducted a t-test.

Finally, the researcher submitted raw data to SPSS 16.0 and compared the results obtained from the pre-test and posttest for both groups to establish the effect of using supplementary readings containing idioms on enhancing students conceptual fluency. She also used histograms and tables in illustrating the results.

\section{Results and Data Analysis}

This part provides the detailed statistical analysis conducted throughout the research.

\subsection{Participants' Mean Score on Pre-test}

Table 1. Descriptive Statistics of the Performance of Control and Experimental Group on Pre-test

\begin{tabular}{cccc}
\hline group & $\mathrm{n}$ & \multicolumn{2}{c}{ Pre- test } \\
\cline { 3 - 4 } & & mean & Std. Deviation \\
\hline Experimental & 15 & 9.9333 & 3.88158 \\
\hline Control & 15 & 8.4667 & 4.27395 \\
\hline Total & 30 & 9.2000 & 4.08023 \\
\hline
\end{tabular}

The difference of mean scores between control and experimental group (1.4666) on pre-test is not significant which shows both groups are approximately at the same level of proficiency in terms of conceptual fluency (see table 1).

\subsection{Frequency of the Obtained Scores of Control and Experimental Groups on Pre-test}

\section{Pre-test (Control Group)}

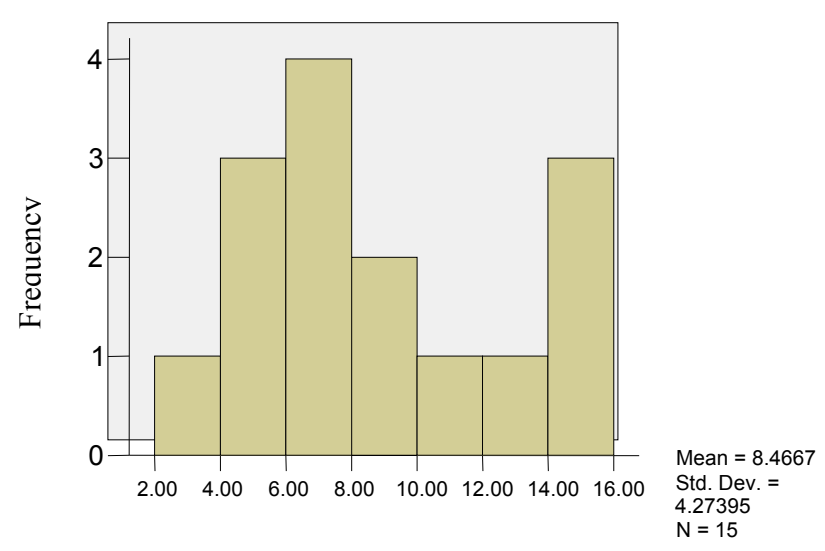

Figure 1. Frequency of the Scores of Control Group on Pre-test 


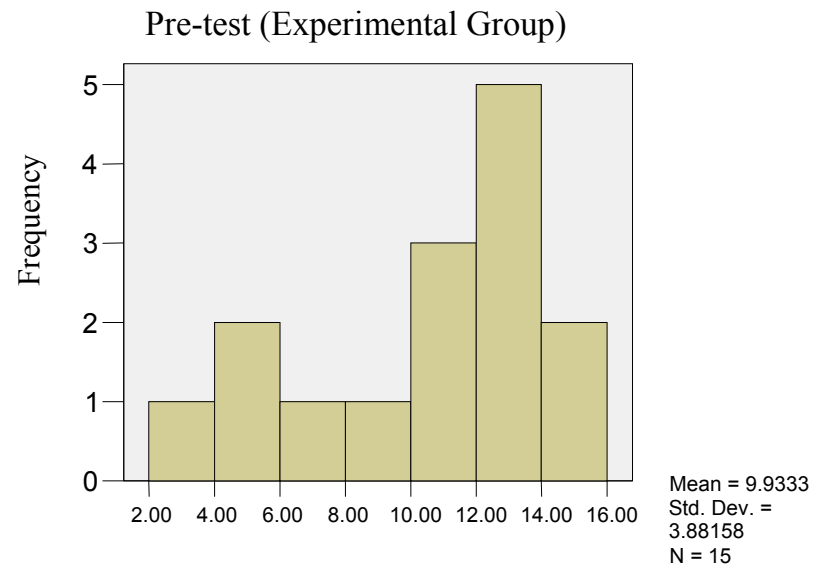

Figure 2. Frequency of the Scores of Experimental Group on Pre-test

The range of scores obtained by both groups out of 30 was more or less the same. Therefore, both groups were approximately at the same level of proficiency on pre-test in terms of conceptual fluency (see figure 1 and 2).

Table 2. T-test

\begin{tabular}{ccc}
\hline $\mathrm{t}$ & $\mathrm{df}$ & Sig. \\
\hline 0.984 & 28 & 0.334
\end{tabular}

In order to ensure that there is no important difference between the control and experimental groups regarding their conceptual fluency, t-test was performed. The results, as Table 2 shows, indicate that that there is no statistically significant difference between experimental and control group $(t 2,30=0.984, p>0.005)$ in their implementation on pre-test.

4. 3 Participants' Mean Score on Post-test

Table 3. Descriptive Statistics of the Performance of Control and Experimental Group on Post-test

\begin{tabular}{cccc}
\hline group & $\mathrm{n}$ & \multicolumn{2}{c}{ Post- test } \\
\cline { 3 - 4 } & & mean & Std. Deviation \\
\hline experimental & 15 & 23.6667 & 3.15474 \\
\hline control & 15 & 20.4000 & 4.71775 \\
\hline total & 30 & 22.0333 & 4.27892 \\
\hline
\end{tabular}

The difference of mean scores a control among and experimental group on post-test is higher than that of pretest $(3.2667>1.4667)$ which shows treatment (supplementary readings containing idioms) was effective for experimental group (see table 3).

4.4 Frequency of the Obtained Scores of Control and Experimental Groups on Post-test

Post-test (Control Group)

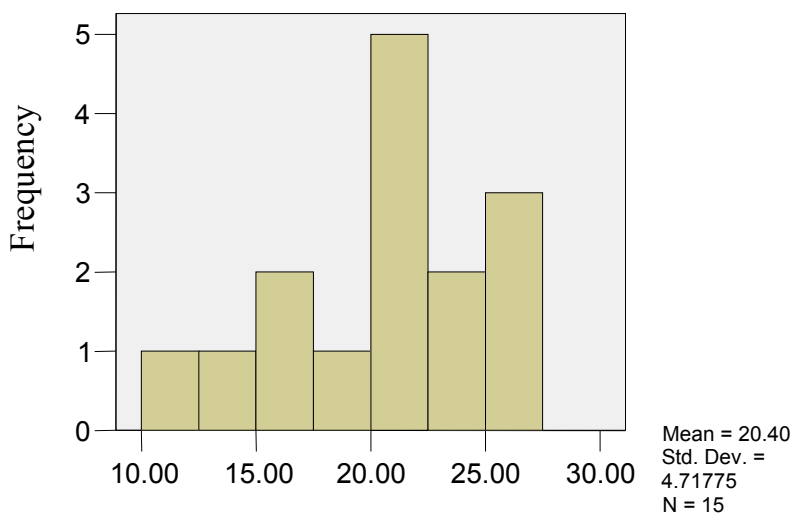

Figure 3. Frequency of the Scores of Control Group on Post-test 


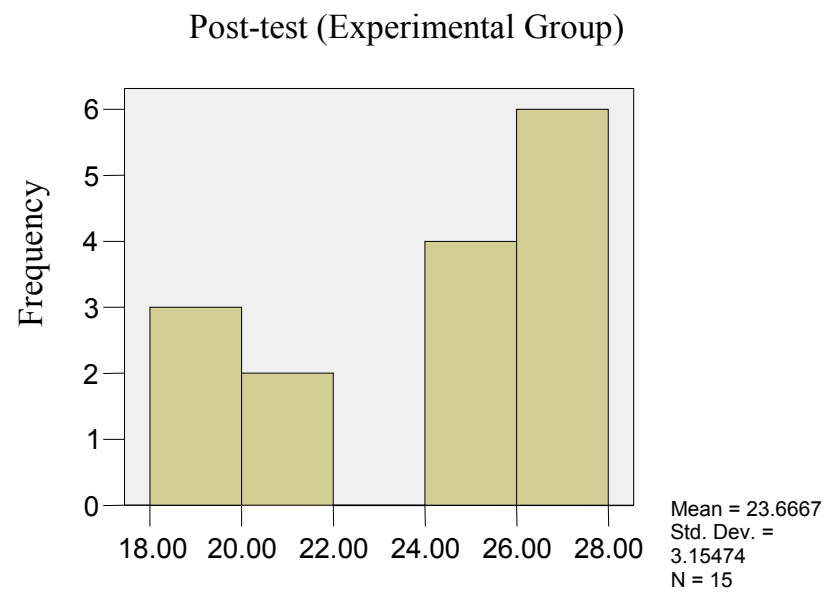

Figure 4. Frequency of the Scores

of Experimental Group on Post-test

In comparison with the pre-test, both groups obtained better scores on post-test (see figures 3 and 4 ). But on the one hand, the lowest and highest scores of experimental group (18 \& 28) are higher than that of control group (10 \& 27.5). And on the other hand, the difference between the highest and lowest scores for experimental group (10) is less than that of control group (17.5). It shows that experimental group was positively affected by the treatment (supplementary readings containing idioms). The scores obtained by experimental group were close to the mean which shows the homogeneity of the group in terms of conceptual fluency. Therefore, the experimental group developed its conceptual fluency in a meaningful way while control group development was not reliable or homogeneous.

\begin{tabular}{ccc}
$\frac{\text { Table 4. T-test }}{\mathrm{t}}$ & $\mathrm{df}$ & Sig. \\
\hline-2.815 & 28 & 0.009
\end{tabular}

In order to ensure that there is a significant difference between the control and experimental group in their performance on post-test, t-test was performed. The results, as Table 4 shows, indicate that there is a statistically important difference between experimental and control group $(t 2,30=-2.815, p<0.005)$ regarding their conceptual fluency on post-test.

\subsection{Comparison of the Performance of Groups on Pre-test and Post-test}

The difference between the Performance of Groups on Pre-test and Post-test is shown in figure 5.

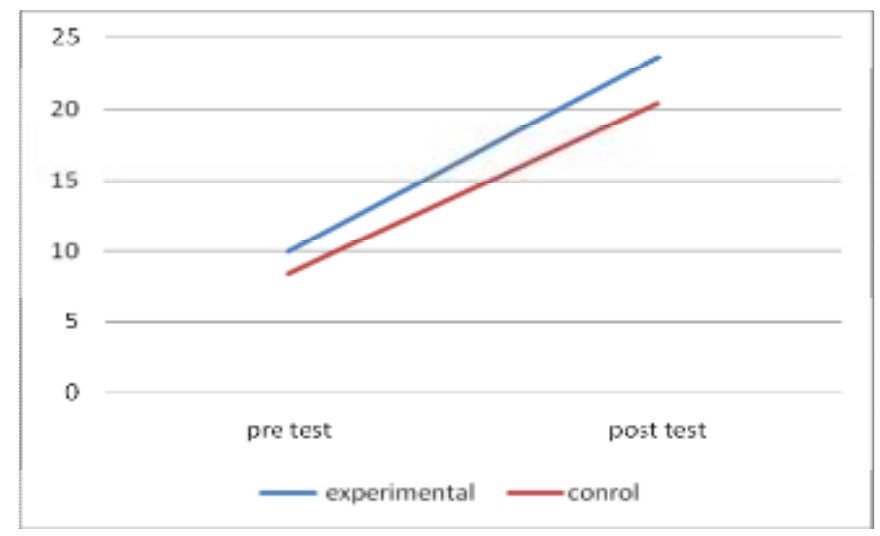

Figure 5. The Difference between the Performance of Groups on Pre-test and Post-test

\section{Discussion}

In this part, the obtained results are discussed in an effort to answer the following research question of the study:

Does using supplementary readings (short stories containing idioms) enhance L2 learners' conceptual fluency?

In order to answer the research question, first, the researcher selected two female lower-intermediate groups of L2 learners in SPLC. The, she held a pre-test containing 30 multiple choice questions. Next, she taught idioms to both control and experimental groups, but provided only experimental group with supplementary readings (short stories 
containing idioms). After that, she held a post-test containing 30 multiple choice questions with a higher level of difficulty comparing to the pre-test. Finally, the researcher compared the results of mean score, frequency of scores, and t-test on pre-test and post-test for both groups to determine the possible development of participants' conceptual fluency in L2.

Comparing participants' mean score on pre- test and post-test shown in tables 4.1 and 4.3 respectively shows that the difference of mean score of control and experimental groups was not significantly different on pre-test, but it showed a significant difference on post-test.

Comparing the results of t-test for pre-test and post-test shown in tables 4.2 and 4.4 concedes the results of mean score for groups.

Close examination of figures 4.1 to 4.4 shows that the range of scores obtained by control and experimental groups on pre-test was approximately the same while this range on post-test was very better for experimental group. The scores obtained by experimental group were also close to the mean which shows the homogeneity of the group in terms of conceptual fluency. Therefore, the experimental group developed its conceptual fluency in a meaningful way while control group development was not reliable or homogeneous.

Considering what was mentioned above, it can be concluded that participants who were at the same level of proficiency in terms of conceptual fluency on pre-test performed differently on the post-test. In other words, experimental group performed better on the post-test. This fact concedes the positive effect of using supplementary readings on enhancing conceptual fluency of L2 learners.

The results obtained from the current study is in line with the results of other studies done on the development of conceptual fluency of L2 learners including Danesi (1995), Talebinezhad (2007), Hashemian and Talebinezhad (2007) and Ghane shirazi and Talebinezhad (2013). All of the mentioned studies like the present study held that it is possible to enhance the conceptual fluency of L2 learners to a meaningful degree.

\section{Conclusions}

The present study was aimed at investigating the effect of using supplementary readings (short stories containing idioms) on developing conceptual fluency of L2 learners. Based on the discussion of the results, the following conclusions were drawn:

- Fluent non-native speakers, even highly competent speakers of English, cannot understand and comprehend idiomatic expressions in different situations as well as native speakers.

- Idioms are an indispensible part of language; they can have several meanings depending on the context within which they are used. so, they are difficult for L2 learners. But they should not be ignored in L2 teaching.

- On the one hand, lack of idiomatic knowledge can have a negative impact on L2 learners' performance in real life situation in L2 setting. On the other hand, learning idiomatic expressions help L2 learners in better communication in the target culture.

- Considering the difficulty of idioms for L2 learners, one cannot expect L2 learners to understand the meanings of idioms outside context or to produce them in their own speech or writing. What is very useful for students to learn and use the expressions is using contexts containing idioms compatible with the students' level of proficiency in L2.

- Comparing idioms in L2 to idioms in learners' native language can be useful in developing conceptual fluency if they are somehow the same.

- Contexts containing idioms with more similarity to the real life situations can have a better effect on the development of conceptual fluency in L2 learners.

So it can be concluded that context plays a major role in the construction of idiomatic meaning and having contextualized idioms in the L2 learners' syllabus can be really useful in enhancing their idiomatic conceptual fluency. Therefore, using supplementary readings in the form of short stories containing idioms has a positive impact on developing conceptual fluency of L2 learners.

\section{References}

Allwright, R. (2006). Six promising directions in applied linguistics. London: Palgrave Macmillan.

Bouton, L. (1994). Can NNS skill in interpreting implicatures in American English improved through explicit instruction? A pilot study on pragmatics and language learning presented at Urbana-Champaign, University of Illinois. http:// www. eric.ed.gov/?id=ED398742

Carter, R. (1998). Vocabulary. Applied linguistics perspectives. New York: Routledge.

Cooper, T. C. (1998). Processing of idioms by L2 learners of English. TESOL Quarterly .Vol.33, pp. 233-262. http:// www.public.iastate.edu

Cruse, A. (2006). A glossary of semantics and pragmatics. Edinburgh: Edinburgh University Press. 
Danesi, M. (1992). Metaphorical competence in second language acquisition and

second language teaching: the neglected dimension. In ALATIS, J.E. (ed.). Georgetown

University Round Table on Languages and Linguistics, pp. 489-500. Washington

DC: Georgetown University Press. http://www.engl.polyu.edu.hk/metaphor/lit/danesi_conceptualfluency.pdf

Danesi, M. (1995). Learning and teaching languages: the role of "conceptual fluency. International Journal of Applied Linguistics.Vol. 5, No. 1. http://_www.engl.polyu.edu.hk/metaphor/lit/danesi_conceptualfluency.pdf

Danesi, M. (2003). Second language teaching. A view from the right side of the brain. Holland: Dordretcht.

De Caro, E. E. R. (2009). The Advantages and Importance of Learning and Using Idioms in English. Cuadernos de Lingüística Hispánica .Vol. 14, pp.121-126. http:// www.dialnet.unirioja.es/descarga/articulo/3618851.pdf

Ellis, N. (1997). Vocabulary acquisition: word structure, collocation, word-class, and meaning. Cambridge: CUP.

Fong, Y. Y. (2006). An experimental investigation to determine the utility of conceptual metaphors and metonymies in enhancing idioms comprehension for EFL undergraduate learners of English. Unpublished master's thesis, Tamkang University, Taipei, Taiwan. http:// www._tkuir.lib.tku.edu.tw

Ghane Shirazi, M., \& Talebinezhad, M.R. (2013). Develpoing intermediate EFL learners' metaphorical competence through exposure. Theory and Practice in Language Studies .Vol. 3, No. 1, pp.135-141. http:// www.ojs.academypublisher.com

Gibbs, R. W. (1994). The poetics of mind. Figurative thought, language and understanding. Cambridge: CUP.

Gibbs, R.W. (1980). Spilling the beans on understanding and memory for idioms in conversation. Memory \& Cognition . Vol.8, pp. 449-456. http:// link.springer.com/article/10.3758\%2FBF03213418

Glucksberg, S. (2001). Understanding Figurative Language. From Metaphors to Idiom. Oxford: OUP.

Hashemian, M, \& Talebinezhad, M.R. (2007). The development of conceptual fluency and metaphorical competence in L2 learners. The Fourth TELLSI Conference. http:// www.linguistik-online.de/.../hashemiannezhad Huizenga, J. (1996). Can you believe it? Oxford: OUP.

Irujo, S. (1993). Steering clear: avoidance in the production of idioms. International Review of Applied

Linguistics.Vol.31, pp. 205-219. http://www.degruyter.com/view/j/iral.1993.31.issue.../iral.1993.31.3.205.xml

Johnson, M. (1987). The Body in the Mind. Chicago: The University of Chicago Press.

Kecskes, I. (1995). Concept formation of Japanese EFL/ESL students. Yamato-matchi: IUJ.

Kecskes, I. (1995). Concept formation of Japanese EFL/ESL students. Yamato-matchi: IUJ.

Kecskes, I. (1999). Conceptual fluency and the use of situation-bound utterances in L2. Journal of Links \& Letters.Vol.2, pp. 145-161. http:// www.ddd.uab.es/pub/lal/11337397n7p145.pdf

Kellerman, E. (1986). An eye for an eye: crosslinguistic constraints on the development of the L2 lexicon. New York: Pergamon Institute of English.

Kellerman, E. (1978). Giving learners a break: native language intuitions as a source of predictions about transferability. Working Papers on Bilingualism, pp.59-92. http:// www._eric.ed.gov/?id=ED153469

koveces and Szabo,(1996).Idioms:a view from cognitive semantics. Journal of Applied linguistics .Vol. 17(3). pp. 326355. http:// www._applij.oxfordjournals.org/content/17/3/326

Lakoff, G. (1987). Women, fire and dangerous things. Chicago: University of Chicago Press.

Lakoff, G., \& Johenson, M. (1980). Metaphors we live by. Chicago: University of Chicago Press.

Lantolf, J. P., \& Thorne, S. L. (2006). Sociocultural theory and the genesis of second language development. Oxford: OUP.

Laufer, B. (1997). What's in a word that makes it hard or easy: some intralexical factors that affect learning of words. Cambridge: CUP.

Littlemore, J., \& Low, G. (2006). Figurative thinking and foreign language Learning. New York: Palgrave McMillan. Marton, W. (1977). Foreign vocabulary learning as problem number one of foreign language teaching at the advanced level. Interlanguage Studies

Bulletin.Vol. 2, pp.33-47. http:// www._www.metaphorik.de/15/andreou-galantomos.pdf

Oppenheim, N. (2000). The importance of recurrent sequences for nonnative speaker fluency and cognition. Ann Arbor: The University of Michigan.

Steinel, M. P., hulstijn, J., \& Steinel, W. (2007). Second language idiom learning in a paired associate paradigm. Effects of direction of learning, direction of testing, Idiom Imageability and Idiom Transparency. Studies in Second Language Acquisition.Vol. 29, pp. 449-484. http:// www._sla.sjtu.edu.cn 
Talebinezhad, M.R. (2007). Conceptual fluency and metaphorical competence in second language acquisition: two sides of the same coin? Journal of Social Sciences and Humanities of Shiraz University.Vol.26, No.4. http://

www.ensani.ir/.../20110226140458

Vanlancker-Sidtis, D. (2003). Auditory recognition of idioms by native and non-native

speakers of English: It takes one to know one. Applied Psycholinguistics .Vol. 24, pp. 45-57.

http://www.researchgate.net/...Auditory_recognition_of_idioms_by_native

Wray, A. (2003). Formulaic language and the lexicon. Cambridge: CUP.

Yorio, C. (1989). Idiomaticity as an indicator of second language Proficiency. Cambridge: CUP.

\section{Appendix 1}

Pre-test

Name:

Complete these parts of stories. Fill in the blanks with idioms.

1. What makes you ......?
a) lose it
b) get rid of
c) take look
d) can't stand
2. I want to ... that smell.
a) can't stand
b) picks up
c) get rid of
d) laugh at

3. A woman is from Vancouver to Victoria.
a) sits down
b) is red in the face
c) after a while
d) taking a ferry

4. What time do you usually to your house or apartment?
a) go back
b) is red in the face
c) slow down
d) calm down

5. They usually at night.
a) run away
b) fall asleep
c) heads for
d) calm down
6. She ........ what she sees.
a) is horrified by
b) makes herself at home
c) has fallen asleep
d) wakes up

7. He .......... the elevator and goes to the street.
a) gets better
b) going after
c) is in a big trouble
d) gets on

8. She is .......... a heart attack.
a) fast sleep
b) turn off
c) get in
d) getting over

9. The business man ............. and crashes in to a lamp post.
a) calms down
b) freaks out
c) pays for
d) on the way

10. We pay for the 50 pagers, puts them in his car, and .......... the office.
a) get rid of
b) as for
c) head for
d) crazy about

11. I Spiders and snakes, aren't you?
a) is in to
b) am fed up with
c) am frightened by
d) after a while

12. Do you want to ............ Mozart?
a) put onb) listen to
c) is crazy about
d) right away

13. Basketball is her favorite sport. She

a) is crazy about b) is steaming

14. She is studying Chinese .......... Japanese.
a) fed up with
b) laugh at
c) as well as
d) look like

c) speed up

d) get along with

15. I'd like to ........, but my boss doesn't want me to.
a) slow down
b) take vacation
c) just in time
d) see eye to eye

16. Can you ............ me, please?
a) save the day b) easy as pie
d) take of a picture

17. You're late again! The boss is steaming, you ........... now.

a) are crazy about b) are hanging on for dear life c) are in big trouble d) are getting along with everyone.

18. Hurry! The plane is going to ......... in ten minutes.
a) Take away
b) take off
c) slow down
d) get better

19. I don't want to play this game anymore. I
a) am fed up with b) drop by
c) was over
20. The cat has my shoes! ............ them ........... from him!
d) made a mistake it.
a) listen...to
b) cheer...up
c) Take...off

21. The teacher will the students early.
a) let out
b) stare at
c) come across
d) belong to

22. The guards had ........... and forgotten to lock it.
a) save the day
b) was over
c) made a mistake
d) show up
23. The bikes .john.
a) belong to
b) stare at
c) think about
d) let out

24. Hurry! If you don't .......... now, you'll be late.
a) lie down
b) get up
c) show up d) drop in 
25. I miss you. Please ............ when you're in town.
a) drop out of
b) make a living $\mathrm{m}$
c) drop in
d) in addition
26. The police will
the crime.

$\begin{array}{ll}\text { a) come across } & \text { b) at times }\end{array}$

27. Please don't me.
a) at once
b) stare at

28. What do you

this book?
a) think about
b) belong to my old car.

29. I'll

b) well off

a) give away

30. Pavel wants to ........... school.
$\begin{array}{ll}\text { a) get mad at } & \text { b) drop out of }\end{array}$

b) drop out of c) see eye to eye

c) so far

c) in addition

c) easy as pie

c) well off d) look in to

d) dirt poor

d) show up

d) lie down

d) break in to

\section{Appendix 2 \\ Post-test}

Name:

Complete these parts of stories. Fill in the blanks with idioms.

1) Carmen, why did you ............. that Tv again? You've watched enough for today.
a) take a look at
b) get rid of
c) turn on
d) can't stand

2) These Programs Turn it

c) can't stand

d) slow down

3) The stylist

b) picks up

pocket.

a) is red in the face

b) picks up

c) takes out

d) sits down

4) Koon man is still angry. I'll never . that salon! he says.
a) go back to
b) at home
c) interested in
d) sits down

5) The woman quietly goes to another room and calls the police "please hurry". She says, "before he wakes up and
a) is horrified by
b) take a nap
c) has fallen asleep
d) runs away

6) The police arrive right away. The thief is still .............., the police arrest the man, walter Morgano, age 35.
a) fall sleep
b) turns over
c) make a mistake
d) taking a nap

7) I can't .............. this cold. I have a headache.
a) get out of
b) get better
c) get over
d) get out of

8) Mr. Ramirez, can I .............. work early today? I'd like to go home and go to bed.
a) get on
b) get out of
c) cheer you up
d) again and again

9) One day, Betty Vaughn, a school teacher, .......... at a mall near her house.
a) speed up
b) on the way
c) goes shopping
d) going after

10) He won't want to ................ the repair to the car.
a) get in
b) Pay for
c) freaks out
d) heads for

11) Hey Giorgio. Why don't you ............. to night. I don't know. I have lots of home work.
a) drop by
b) frightened by
c) listen to
d) as for

12) I'll call you

.. to see how it's going.
a) after while
b) lots of
c) right away
d) take off

13) The Bubble lady, as she is called, says that life is full of tragedy. "This is a way to people aren't laughing at.
a) is into
b) are crazy about
c) cheer...up
d) as well as

14) You are to the Grand can you? How wonderful! Can I come?
a) won't believe your eyes
b) get in
c) taking a vacation
d) going after

15) I was there a few years ago and loved it. Do you have your camera? You'll want to.....
a) on vacation
b) are in big trouble
c) take pictures
d) take away

16) We're late! We have to a little.
a) slow down
b) crazy about
c) speed up
d) as well as

17) We'll if we're late for school again. Ms. Vine will get angry.
a) be in big trouble
b) as for
c) going after
d) after a while

18) Robert Noland doesn't ............. his neighbor.
a) again and again
b) get along with
c) keep on
d) going after

19) Why are the police ..............me?
a) is steaming
b) is fed up with
c) take off
d) is in to

20) People in Bodengraven love to ............ at their local Mc Donald's restaurant.
a) later on
b) easy as pie
c) spend time
d) think a bout

21) It was time to ............. the hostages.
a) let out
b) made a mistake
c) was over
d) fall asleep

22) One evening, Tracey schelans ki ................ and fell asleep.
a) lay down
b) belong to
c) take a took
d) turn off 
23) A few hours later, she heard a loud crash. She .................. and looked out the window.
a) got up
b) showed up
c) saved the day
d) runs away

24) Hey, Gianni.

Where's my car? You said you were returning it today.
a) at once
b) what's going on
c) get mad at
d) at least

25) Paco, calm down. Some one hit it in a parking lot. I reported it to the police and they're man.
a) a smell a rat
b) at times
c) looking in to
d) see eye to eye

26) Mom, I want to do something to my hair changing the color.

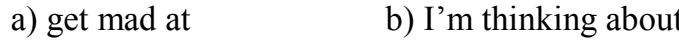

27) It's boring. I love red hair. Purple hair

c) be longed to

d) show up

a) is in

b) at times too.

28) Don Stephensen is ................

a) in addition $\quad$ b) gives away
29) Now Stephenson has a home and

c) showed up

d) be in

c) one in a million

d) freaks out

a) makes a living b) see eye to eye as a mechanic.

30) What ............ When you are sad?
a) cheers you up
b) is in to
c) are laughing at d) take away

c) can't stand

d) calms down 